This is the final peer-reviewed accepted manuscript of

GRAHAM, ALEXANDER GUNDLACH; Garofalo, Paolo S.; Schwarz, Gunnar; REDI, DANIELE; Günther, Detlef: High-Resolution, Quantitative Element Imaging of an Upper Crust, Low-Angle Cataclasite (Zuccale Fault, Northern Apennines) by Laser Ablation ICP Time-of-Flight Mass Spectrometry. GEOSTANDARDS AND GEOANALYTICAL RESEARCH 42. ISSN 1639-4488

DOI: $10.1111 /$ ggr.12233

The final published version is available online at: $\underline{\text { http://dx.doi.org/10.1111/ggr.12233 }}$

Rights / License: The terms and conditions for the reuse of this version of the manuscript are specified in the publishing policy. For all terms of use and more information see the publisher's website. 


\title{
High-resolution, Quantitative Element Imaging of an Upper Crust, Low-angle Cataclasite (Zuccale Fault, Northern Apennines) by Laser Ablation ICP Time-of-Flight Mass Spectrometry
}

\author{
Alexander Gundlach-Graham $(1, \uparrow)^{*}$, Paolo S. Garofalo $(2, \uparrow)^{*}$, Gunnar Schwarz $(1)$, \\ Daniele Redi (2) and Detlef Günther (1) \\ (1) Laboratory of Inorganic Chemistry, Department of Chemistry and Applied Biosciences, ETH Zurich, Zurich, Switzerland \\ (2) Dipartimento di Biologia, Geologia ed Ambiente, Università di Bologna, Bologna, Italy \\ * Corresponding authors. e mails: graham@inorg.chem.ethz.ch and paolo.garofalo@unibo.it
}

Laser ablation inductively coupled plasma time-of-flight mass spectrometry (LA-ICP-ToF-MS) was used to generate quantitative elemental images of a mineralogically and texturally complex fault rock of the Northern Apennines of Italy (Zuccale Fault, eastern Island of Elba). Using LA-ICP-ToF-MS combined with a low-dispersion LA cell, we were able to generate large format $(4 \mathrm{~mm} \times 2 \mathrm{~mm})$, high-resolution $(5 \mu \mathrm{m})$, high dynamic range $\left(110^{6} \mu \mathrm{g} \mathrm{g}^{-1}\right)$ and quantitative multi-elemental two-dimensional compositional maps within a data acquisition time of a few hours. To quantify element mass fractions across the heterogeneous sample of the Zuccale Fault, we used a $100 \%$ species-mass normalisation approach that took into account different mineral phases across the specimen. To assign mineral phase directly from LA-ICP-ToF-MS data, we exploited the segregation of sulfur and calcium between distinct phases to threshold element images and develop mineral-phase-specific masks. Moreover, we demonstrate agreement between elemental mass fractions determined by LA-ICP-ToF-MS imaging with $100 \%$ normalisation quantification and conventional LA-ICP-MS analysis with internal standard element-based quantification. Finally, we discuss how this elemental imaging provides unique insights into the genesis of the Zuccale Fault.

Keywords: low angle faults, Zuccale fault, cataclasites, laser ablation inductively coupled plasma time of flight mass spectrometry, element imaging.

After decades of developments and applications, laser ablation inductively coupled plasma mass spectrometry (LA ICP MS) is one of the most established analytical techniques for Earth Science research (Heinrich et al. 2003, Pettke et al. 2012, Sylvester and Jackson 2016). Specifically, two dimensional (and sometimes three dimensional) elemental mapping of trace, minor and major element mass fractions by LA ICP MS allows unique insights into geological pro cesses and mineral properties (Woodhead et al. 2007, Large et al. 2009, Ulrich et al. 2009, Ubide et al. 2015, Petrus et al. 2017).

Recently, high resolution $(<10 \mu \mathrm{m})$ LA ICP MS based elemental imaging has emerged as a promising method for the simultaneous determination of quantitative maps of major, minor and trace elements in solid samples, including biological tissues and geological samples (Gundlach Graham and Günther 2016, Van Malderen et al. 2016). This trend towards high resolution LA ICP MS elemental imaging has been supported by recent developments in low dispersion transport of laser ablated aerosols (Wang et al. 2013, Douglas et al. 2015, Van Malderen et al. 2015). In particular, the combination of ICP ToFMS with low dispersion LA enables improved limits of detection compared with previous LA ICP ToF MS setups and offers benefits of simultaneous full spectrum detection (Schilling et al. 2007) and improved speed of analysis compared with LAICPMS with more 
conventional scanning based mass analysers (Heinrich et al. 2003).

Elemental imaging by shot resolved LA ICP ToF MS has been described in several publications (Giesen et al. 2014, Burger et al. 2015, 2017, Gundlach Graham et al. 2015, Bussweiler et al. 2017, Van Malderen et al. 2017), and for interested readers, details of the instrumental set up, data acquisition strategy and advantages and capabilities of the method are provided therein. Briefly, in pulsed resolved LA ICP ToF MS imaging, the aerosol generated from each LA shot is transported from the LA site to the ICP through a LA 'tube cell' designed to transport aerosol particle clouds with minimal dispersion (Wang et al. 2013). The sample is scanned underneath the pulsed laser, and individual transient signals correlated with each LA spot are assigned to laser position. In this way, two dimensional elemental intensity images, which have dimensions equal to number of LA shots per line by the number of lines, are generated. Transient peaks from single LA shots have peak widths of less than $50 \mathrm{~ms}$ at full width $1 \%$ maximum. This low dispersion transport of ablated aerosols into the ICP eliminates pulse to pulse mixing (Woodhead et al. 2007, van Elteren et al. 2013), which is a common cause of image blurring and can limit lateral resolution (van Elteren and Vanhaecke 2016). While the transport of very short LA generated aerosol packets is advantageous for obtaining high lateral resolution, improved speed of analysis and improved signal to noise ratios, accurate multi isotope/element measurement of these fast transient signals requires simultaneous mass analysis at high temporal resolution (Leach and Hieffje 2002). Currently, the only mass analyser design with sufficient full mass spectrum acquisition speed is ToF.

In this study, we follow the route outlined in Burger et al. (2017) for elemental imaging of heterogeneous geological samples with more emphasis on data processing. We report on a previously undocumented, mineralogically and chemically complex rock from the core of an upper crustal, low angle Fault (Zuccale Fault, northern Apennines). This specific sample is a cataclasite because it formed during intense rock wearing during which a foliated texture formed due to deformation driven crystallisation. The sample hosts $\mathrm{Pb} \mathrm{Zn} \mathrm{Fe}$ sulfides, ferroan dolomite, ochraceous oxides ( $\mathrm{FeO}>50 \%$ $\mathrm{m} / \mathrm{m}$ ) and amorphous silica. We document the chemical composition of this mineral assemblage by combining scanning electron microscopy energy dispersive $X$ ray spectroscopy (SEM EDS), transmission electron microscopy (TEM) and LAICPToFMS elemental imaging with supporting analysis by hole drilling LA ICP ToF MS. We demonstrate that LA ICP ToF MS imaging portrays the spatial distribution of an unprecedented number of major, minor and trace chemical components of the fault rock (e.g., $\mathrm{SiO}_{2}, \mathrm{Al}_{2} \mathrm{O}_{3}$, $\mathrm{FeO}, \mathrm{Pb}, \mathrm{Zn}, \mathrm{Sb}, \mathrm{Ga}$, In, Ag). Importantly, the high fidelity of these elemental images allows for straightforward spatial comparison between the quantitative element distribution and the sample texture as observed by optical microscopy. In many cases, element distributions effectively portray rock texture, which provides critical insights into the rock formation processes. Further, we also demonstrate an approach to ascertain mineral and phase information directly from LA ICP ToF MS images in order to accurately quantify element mass fractions within a challenging multiphase geological specimen.

\section{Geological setting and studied sample}

The studied sample is from the Island of Elba of the northern Tyrrhenian Sea (Figure 1), which consists of a stack of sedimentary and metamorphic tectonic units intruded by a variety of magmatic rocks of complex origin (Keller and Coward 1996, Poli and Peccerillo 2016). The sample is from the Zuccale Fault, which is a gently east dipping fault whose geometry and structural features were interpreted as indicative of normal faulting (Keller and Coward 1996, Collettini and Holdsworth 2004). The fault was likely active during and after the emplacement of the skarn ore bodies of eastern Elba (6.4 5.3 Ma, Tanelli et al. 2001). Specifically, the rock section studied here is from the western sector of the Calamita Peninsula (Figure 1), which is the place where the Zuccale fault occurs mainly as a foliated cataclasite with minor secondary dolomite replacement (cf. Musumeci et al. 2015). The sampled level of the fault corresponds rock unit 'L4' of Smith and Faulkner (2010) and corresponds to the fault core.

The sample (PF12) is a foliated cataclasite in which thin sulfide bands made of sphalerite and minor galena alternate with dolomite bands, amorphous silica and an ochraceous phase (Figure 2ac). Chalcopyrite occurs as blebs or anhedral inclusions within sphalerite. Dolomite makes about $2025 \% \mathrm{v} / \mathrm{v}$ of the entire sample, while the sulfides have an overall modal abundance of about $10 \% \mathrm{v} /$ $v$. The ochraceous phase (either opaque or with a deep red interference colours in transmitted light) appears as an aggregate of anhedral crystals that can hardly be distinguished from each other. The ochraceous phase as a whole has a modal abundance of about $40 \% \mathrm{v} / \mathrm{v}$.

With a modal abundance of $1015 \% \mathrm{v} / \mathrm{v}$, amorphous silica is closely associated with the ochraceous phase and has a distinct tendency to form roundish aggregates (clumps, Figure 2c) with a diameter between $\sim 30$ and $300 \mu \mathrm{m}$. The optical properties of the clumps are those of an amorphous 


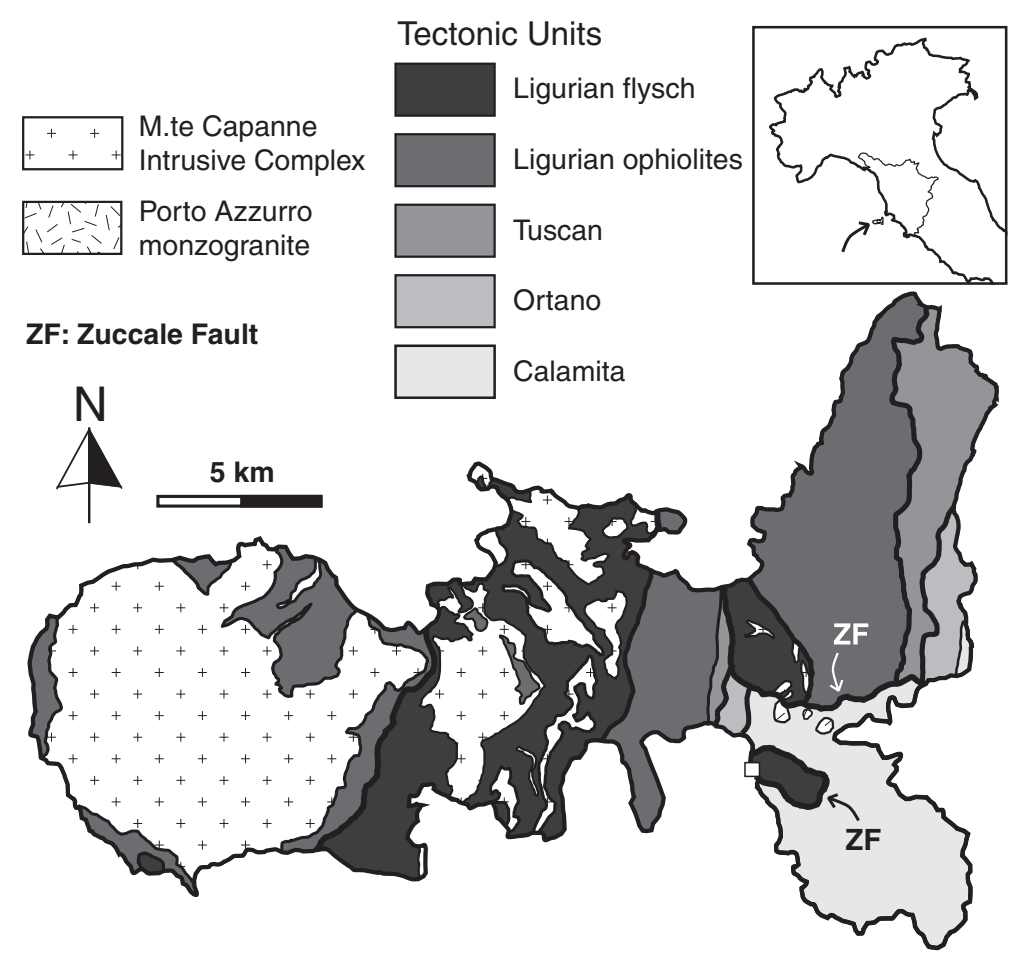

Figure 1. Tectonic sketch map of the Island of Elba with locations of main tectonic structures (modified after Musumeci et al. 2015). The tectonic units listed in the legend are reported following their order in the structural pile, that is, the shallowest is listed on top and the deepest at bottom. Thick lines mark the tectonic contacts between the rock sequences. Note the location of the Zuccale fault in the eastern side of the island, and the position of the collected sample marked by the white square.

phase, as confirmed by TEM diffraction patterns (Figure 2e, see below). Minor mineralogical constituents of PF12 are euhedral quartz and rutile.

\section{Experimental procedure}

\section{Scanning electron microscopy (SEM) and X-ray energy dispersive analysis}

The SEM EDS analyses were performed at the Department of Biology, Geology and Environment of University of Bologna using a Phillips 515 system equipped with an EDAX DX4. Single spot EDX analyses were performed at $15 \mathrm{kV}$ accelerating voltage and $2 \mathrm{nA}$ beam current for 100 live second counting time. Concentrations of major chemical components were calculated on an anhydrous basis with ZAF corrections and using natural silicates and oxides for calibration.

\section{Transmission electron microscopy}

High magnification imaging and selected area diffraction experiments were carried out at the Department of Physics and Astronomy of the University of Bologna using a
Phillips M400T Transmission Electron Microscope. Fine grained powders of the two studied samples were collected with a sharp tungsten carbide tip in areas where petrographic evidence for amorphous silica was gathered (i.e., in areas where 'silica clumps' or aggregates of amorphous silica were most abundant, see below). This powder was then deposited by evaporation of distilled water on lacy carbon films (200 mesh) supported by copper grids. Typical accelerating voltage for TEM diffraction experiments was $80 \mathrm{kV}$, and imaging magnification in the 80000100000 range (camera constant: 800 ).

\section{LA-ICP-ToF-MS imaging}

Elemental imaging was performed on a commercially available ICP ToF MS instrument (icp ToF; ToFWERK AG, Thun, Switzerland) combined with an argon fluoride (ArF) excimer LA system (193 nm, GeoLas C; Lambda Physik, Göttingen, Germany) and the low dispersion LA 'tube' cell (Gundlach Graham et al. 2015). Laser ablation was conducted in a helium atmosphere (99.999\%; PanGas AG, Dagmersellen, Switzerland), and ablated aerosols were carried to the ICP MS in a stream of argon gas $(99.996 \%$; 

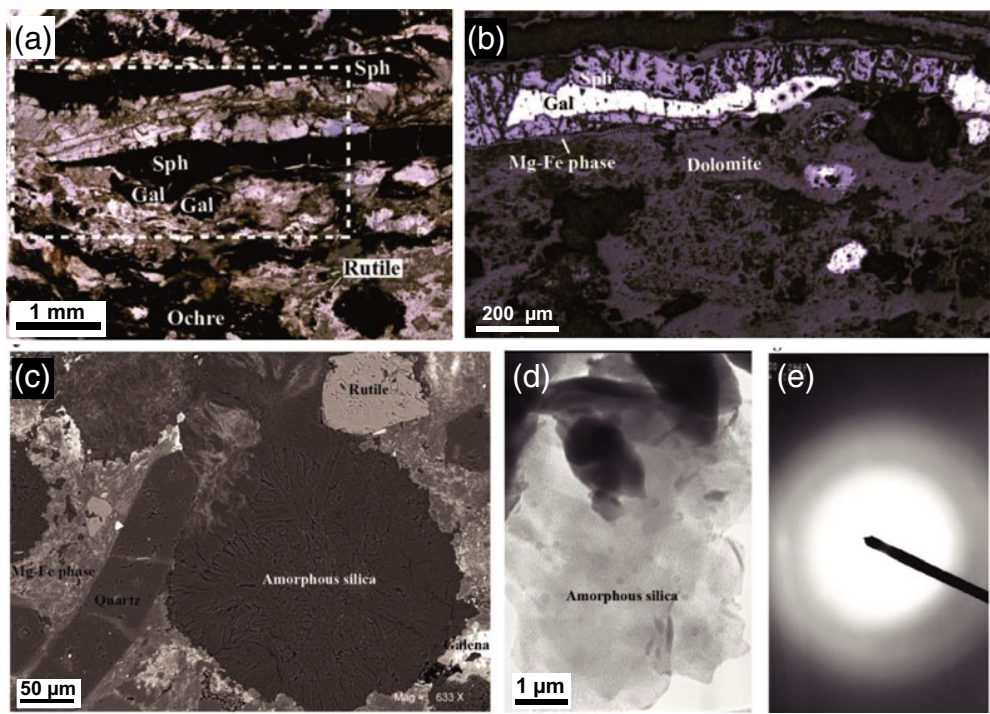

Figure 2. Textural and mineralogical characteristics of the Zuccale fault rock sample PF12. (a) Petrographic micrograph of the sample with region imaged by LA-ICP-ToF-MS outlined by rectangle. (b) Reflected light photomicrograph of a thin galena-sphalerite cataclasite level mantled by the Fe-Mg ochraceous phase and very irregular aggregates of carbonate and amorphous silica. There is a textural contrast between the linear fabric of the sulfide vein and mantling ochraceous layer, and the roundish fabric made by the silica and carbonate aggregates. (c) Association between a typical clumpy, rosette-like aggregate of amorphous silica with quartz, rutile, anhedral galena and Mg-Fe ochraceous phase (BE-SEM image). (d) TEM photomicrographs of shards of amorphous silica. (e) Selected-area TEM diffraction pattern of the silica of sample PF12. Note the occurrence of broad and diffuse diffraction halos, which systematically decrease their intensity from the centre of the pattern. Such evidence, combined with the simultaneous lack of diffraction spots, shows that the analysed phase is truly amorphous.

PanGas AG). The gas dynamics of the LA tube cell allowed for low dispersion transfer of ablated aerosol into the ICP, such that single shot LA signals were between 10 and $50 \mathrm{~ms}$ (full width at $1 \%$ maximum) in duration. Differences in ablated aerosol transients were evident when ablating diverse matrices; as ablation yield changes with matrix, so does transient duration.

As reported in Table S1, low dispersion aerosol transport with the tube cell required fairly high gas flow rates into the injector (1.7 I min $\mathrm{me}^{-1} \mathrm{He} 0.84 \mathrm{I} \mathrm{min}^{-1} \mathrm{Ar}$ ). These gas flow rates are typical of our low dispersion LA system (Gundlach Graham et al. 2015, Burger et al. 2017) and promote low dispersion aerosol transport to facilitate optimum pulse to pulse separation of ablated signals and thus improve lateral resolution. However, it should be mentioned that, because low dispersion aerosol transport preserves high instantaneous concentration of ablated aerosols into the plasma, it could be difficult to measure of high mass matrix elements for which ToF MS has higher sensitivity. In particular, in the current study, we found that ablation of galena in the PF12 sample caused detector saturation of $\mathrm{Pb}$ isotope signals even with $5 \mu \mathrm{m}$ LA spot diameter. To avoid detector saturation by $\mathrm{Pb}$ isotopes, the transmission of ions centred on $\mathrm{m} / \mathrm{z} 215$ was attenuated using the RF notch filter. These notch settings were chosen to sufficiently attenuate $\mathrm{Pb}$ isotope signals while minimising attenuation of other analyte signals of interest, that is, ${ }^{197} \mathrm{Au}^{+}$. In Figure S1, the attenuation of selected isotopes by the notch filter is presented. As seen, notching high mass $\mathrm{Pb}$ isotopes attenuates a broad $\mathrm{m} / \mathrm{z}$ range, with signal attenuation of $10 \%$ still apparent at $\mathrm{m} / \mathrm{z}$ 165. The effect of the notch setting is also apparent in signal ratios, such as ${ }^{232} \mathrm{Th}^{16} \mathrm{O} /{ }^{232} \mathrm{Th}$ and ${ }^{238} \mathrm{U} /{ }^{232} \mathrm{Th}$ ratios, which are both artificially high due to the band pass of the notch filter (Table S1). While we addressed intense $\mathrm{Pb}$ isotope signals here via attenuation by RF notch filter, a second possibility would have been to temporally stretch the ablated aerosol signals, albeit with a loss in imaging speed or lateral resolution. For elemental imaging of heary metal matrices such as galena, compromises must be made with the LA ICP ToF MS systems between absolute sensitivity or speed of analysis and lateral resolution.

To generate the rectangular grid of LA spot locations used to generate elemental images, we scanned the sample underneath a pulsed laser beam so that adjacent circular LA 
spots were lined up edge to edge both across each line scan between consecutive line scans. Laser shot resolved and complete elemental mass spectra were obtained with the ToF mass analyser at a time resolution of $2 \mathrm{~ms}$. At this mass spectral acquisition speed and a LA frequency of $20 \mathrm{~Hz}$, signals from consecutive LA events were well separated as shown in Figure 3, signal intensity from individual ablation events decreases by up to four orders of magnitude within the $50 \mathrm{~ms}$ between laser shots. ICP ToF MS data were collected continuously and not synchronised with the LA events. Typical LA and ICP operation conditions are listed in Table S1.

Following baseline subtraction and mass peak integration, LA pulse resolved ICP ToF MS data were segmented offline with a custom written MATLAB (version R2015a; MathWorks, Natick, MA, USA) program to generate integrated pixel specific intensities; MATLAB scripts are available from the author upon request. Detailed evaluation on the impact of baseline subtraction on abundance sensitivity performance and accuracy of quantification for LA ICP ToF MS can be found elsewhere (Burger et al. 2017, Hendriks et al. 2017). Figure 3 provides representative data and a schematic of the LA ICP ToF MS elemental image generation approach. A laser spot diameter of $5 \mu \mathrm{m}$ was used to image the thin section with adequate resolution to visualise rock texture and separate individual phases. An area of $4 \times 2 \mathrm{~mm}$ was imaged to produce $800 \times 400$ pixel images for each mass channel. To keep data file size manageable, the complete elemental image was acquired in forly subsections of $4000 \times 50 \mu \mathrm{m}$ (10 rows of 800 spots), which were stitched together during data processing. The single shot limits of detection (LODs) obtained for LA reference material GSE $2 \mathrm{G}$ with a $5 \mu \mathrm{m}$ spot diameter are provided in Figure S2; for quantified images, pixels with mass fractions below these LODs are colour coded in black.

In order to translate pixel intensity images into quantified elemental images, a 100\% mass normalisation quantification strategy (Gratuze 1999, Liu et al. 2008) based on the stoichiometry of the oxide, carbonate and sulfide forms of each element was implemented. In this strategy, the signals from the reference material, GSE 2G, were first used to determine elemental sensitivities, that is, counts pixel $^{-1}$ mass-fraction $^{-1}$. Elemental mass fractions were then determined according to a conventional external calibration approach for LA ICP MS (Longerich et al. 1996). This quantification is described by Equation (1), where $R$ is the response of each isotope $i$ in counts per LA shot, $c$ is the mass fraction of the element represented by isotope $i$, reference refers to the reference material, subscript sample refers to the sample and IS denotes the internal standard element.

$$
\left.c_{i, \text { sample }}=s_{i, \text { sample }}\left[\frac{c_{i, \text { reference }}}{R_{i, \text { reference }}} \frac{R_{\mathrm{IS} \text {, reference }}}{R_{\mathrm{IS} \text {,sample }}} \times \frac{c_{\mathrm{IS} \text {,sample }}}{C_{\mathrm{IS} \text {,reference }}}\right)\right]
$$

The reference material used was GSE 2G, and the sum of all isotope signals was used as the internal standard (IS); an arbitrary mass fraction of 1 was used for the $C_{\mathrm{IS} \text {,sample in }}$ the initial mass fraction determination for each element in each image pixel.

$c_{i, \text { sample }}=s_{i, \text { sample }}\left[\frac{c_{i, \text { reference }}}{R_{i, \text { reference }}} \times \frac{\sum_{i}^{n} R_{i, \text { reference }}}{\sum_{i=1}^{n} R_{i, \text { sample }}} \times \frac{c_{\text {IS,sample }}}{\sum_{i=1}^{n} c_{i, \text { reference }}}\right]$

To correct for the presence of oxide, carbonate and sulfide groups, a correction factor, $K_{i}$ was applied at each pixel depending on its composition as oxide, carbonate or sulfide (see Results and Discussion section for detail on how phase was assigned for each pixel). The 100\% normalised mass fraction of each element $i$ was calculated by multiplication of the originally determined mass fraction by the $100 \%$ normalisation correction factor. A list of the isotopes used for $100 \%$ quantification and the correction factors used is supplied in Table S2.

$$
\left.c_{i, \text { sample }, 100 \% \text { nom }}=c_{i, \text { sample }} \times \sum_{i}^{n}\left(c_{i, \text { sample }} \times K_{i, \text { species }}\right)\right)^{-1}
$$

\section{Spot analysis by hole-drilling LA-ICP-ToF-MS}

Spot analyses of a selected silica phase of the previously imaged and repolished sample were performed by conventional hole drilling LA ICP MS experiments (Hattendorf and Günther 2014). For this analysis, the external reference sample, NIST SRM 610, was ablated in duplicate before and after ablation of the rock sample to determine isotope sensitivities and correct for instrument drift. Typical LA and ICP MS operation conditions are listed in Table S3. Quantification of element mass fractions was performed by an internal standardisation approach (Longerich et al. 1996) with ${ }^{29} \mathrm{Si}$ as internal standard using the data reduction soffware SILLS (Guillong et al. 2008). Silicon mass fraction of this phase was determined externally by SEM EDS analysis. Preferred values for elemental mass fractions in NIST SRM 610 were taken from the GeoReM database (Jochum and Nohl 2008). Prior to analysis in SILLS, the mass spectral 
(a)
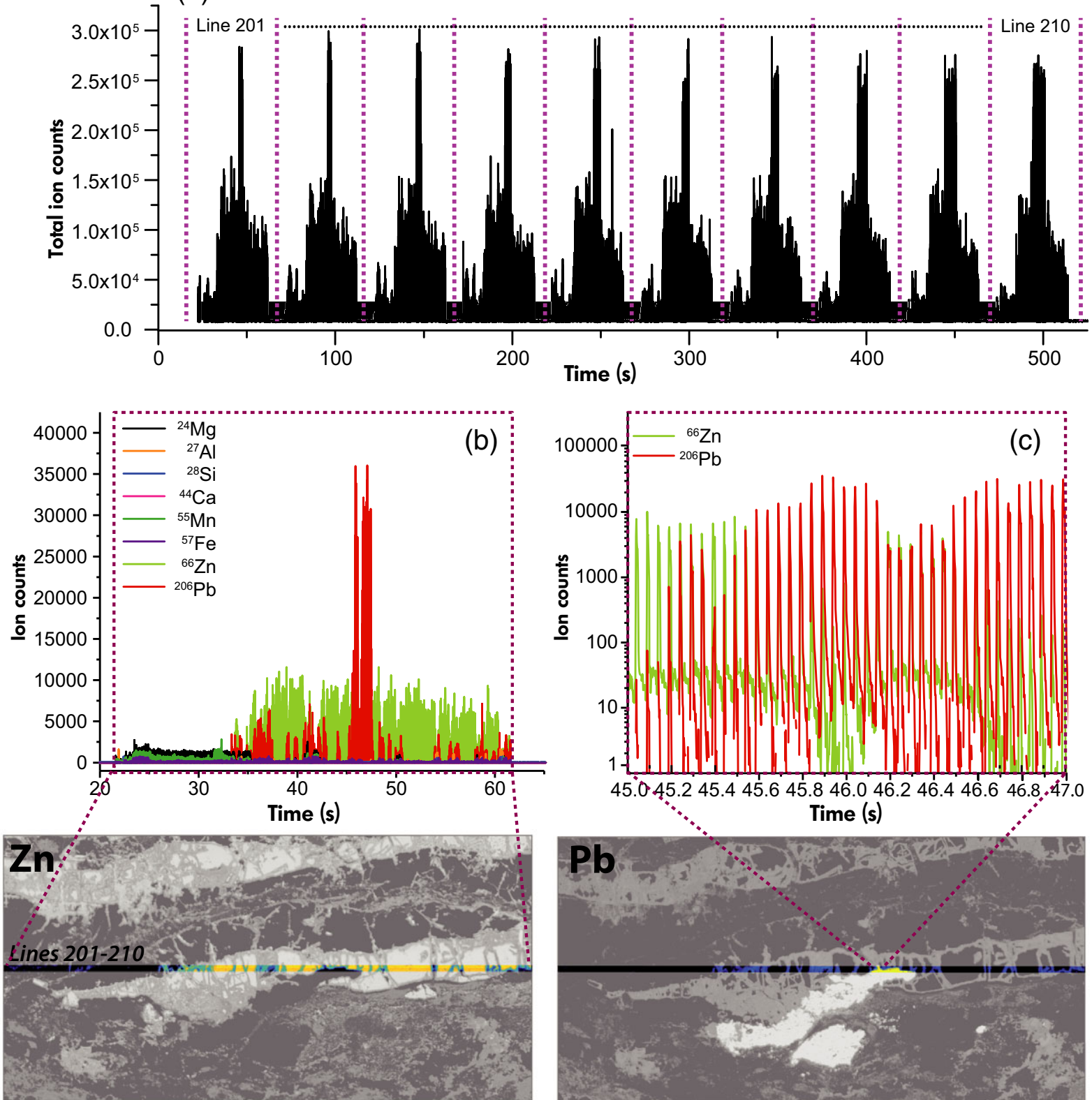

Figure 3. Data acquisition and analysis strategy for high-resolution LA-ICP-ToF-MS imaging. For element-image acquisition, ICP-ToF-MS data are collected continuously while sequential line scans of LA shots are performed at a frequency of $20 \mathrm{~Hz}$. Each ICP-ToF-MS file is composed of ablated signal from 10 consecutive lines, that is, data from 8000 laser shots. The entire image is recorded in forty ICP-ToF-MS files, each with data for ten lines. In (a), total-ion line scan data from ten lines of PF 12 image are shown; 400 line scans each composed of 800 LA events compose the elemental images of PF12. (b) Zoom-in of LA-ICP-ToF-MS data from the 201 st line scan of the elemental images shows the multi-elemental/isotopic ToF-MS data obtained from each 5- $\mu \mathrm{m}$ LA shot (only select isotope signals are shown). (c) Zoom-in on $2 \mathrm{~s}$ (i.e., forty LA shots) of ICP-ToF-MS time traces of isotopes of two major elements, Zn and $\mathrm{Pb}$, plotted on a $\log _{10}\left(\right.$ intensity) scale. As seen, ${ }^{206} \mathrm{~Pb}$ signal decreases by almost four decades between ablation events; ${ }^{66} \mathrm{Zn}$ signal shows more carry-over between ablation events, but signal decline is still over three orders of magnitude. Signals from each LA event were integrated across $50 \mathrm{~ms}$ to determine the signal intensities in each pixel. Images with signals from the two most intense ToF-MS mass channels $\left({ }^{66} \mathrm{Zn}^{+}\right.$and $\left.{ }^{206} \mathrm{~Pb}^{+}\right)$are shown with pixels from lines 201210 of the elemental images highlighted. 
peaks in each ToF MS spectrum were baseline subtracted and then integrated using Tofware software (Tofware, ToFWERK AG, run on IGOR Pro, ver. 6.3.6.4; WaveMetrics, Inc., Portland, OR, USA). Integrated ToF MS peak signals were extracted as isotope specific signal time traces for quantification in SILLS.

\section{Results and discussion}

\section{Phase-specific $100 \%$ normalisation quantitative elemental imaging by LA-ICP-ToF-MS}

As shown in Figure 2, the PFl2 sample is extremely heterogeneous: its mineral assemblage is represented by amorphous silica, an Mg Fe rich 'ochraceous' phase, carbonate (i.e., dolomite), sphalerite and galena. The fault rock is also texturally heterogeneous, which poses a challenge for quantitative LAICP ToFMS imaging. Indeed, no single element is present at known mass fractions across an individual line scan and even the major elements show a broad mass fraction variation. Due to the absence of a suitable internal standard, we chose to employ $100 \%$ mass normalisation quantification strategy.

To date, the quantification of multiphase heterogeneous geological samples has been achieved through the use of reference materials combined with secondary methods to provide internal standard mass fractions of the sample (Paul et al. 2014). These researchers applied (among other mineral segmentation approaches) principle component analysis to identify and assign different phases within a multiphase sample imaged by LA ICP MS. They quantified elements within these phases using different reference materials and internal standards depending on the phase's composition.

While 100\% normalisation quantification has been demonstrated to produce accurate LA ICP MS analysis of materials of known and constant matrix stoichiometry (Tabersky et al. 2013), only a few publications (Gundlach Graham et al. 2015, Burger et al. 2017) report 100\% mass normalised quantification across a heterogeneous material. Mass quantification by $100 \%$ normalisation is particularly well suited for ToFMS because complete element detection ensures all measurable elements are accounted for in the normalisation calculation (Leach and Hieftie 2001). However, with ICP ToF MS, some geologically significant elements, such as lithium, boron, carbon, oxygen or sulfur, are difficult or impossible to measure due to background species and reduced sensitivity for low masses. An accurate 100\% normalisation approach must, therefore, include the known major element stoichiometries of the sample at the position from which each LA ICP MS signal was obtained. In the studied sample, the three most predominant phases are oxide, carbonate and sulfide, which have anionic components of $\mathrm{O}^{2-}, \mathrm{CO}_{3}^{2}$ or $\mathrm{S}^{2-}$, respectively. Clearly, the anionic component of a phase's molecular structure often makes up a large fraction of the total mass ablated and inaccurate assignment of major element stoichiometries will adversely affect quantification. For instance, in the Zuccale Fault rock, iron exists as FeO, $\mathrm{FeCO}_{3}$ and $\mathrm{FeS}$ within the ochraceous phase, carbonate and sphalerite, respectively. If all Fe signals were quantified as $\mathrm{FeO}$, but a particular phase actually was composed of $\mathrm{FeCO}_{3}$, then the iron mass fraction in that phase would be quantified as about $30 \%$ too high; likewise, the spuriously elevated normalisation factor would cause systematic over estimation of mass fractions for all other elements.

To assign element speciation and phase stoichiometry at the single pixel level, we used single isotope intensities of ${ }^{32} \mathrm{~S}^{+}$and ${ }^{44} \mathrm{Ca}^{+}$as indicators of pixels associated with the sulfide and carbonate domains, respectively. In Figure 4, the histograms for the ${ }^{32} \mathrm{~S}^{+}$and ${ }^{44} \mathrm{Ca}^{+}$are presented to show how the threshold levels for the sulfide and carbonate domains were chosen. Specifically, if ${ }^{32} \mathrm{~S}^{+}$signal was above 1254 counts, the sulfide domain was assigned to that pixel; if ${ }^{44} \mathrm{Ca}^{+}$was above 132 counts, the carbonate domain was assigned; and all other pixels were quantified as oxides. The use of single isotope signals of ${ }^{44} \mathrm{Ca}$ and ${ }^{32} \mathrm{~S}$ to divide pixels into appropriate mineralogical domains is adequate for the given specimen. However, we do not expect domain segregation by thresholds of ${ }^{44} \mathrm{Ca}$ and ${ }^{32} \mathrm{~S}$ signals to be generally applicable for all other geological sample types. Instead, for any given geological samples, characteristic isotopes (based on stoichiometry of given mineral phases) need to be identified to separate domains. Domain assignment should also be independently identified by combining petrographic documentation and prior geolog ical knowledge. Full spectrum data available with LA ICP ToF MS for each pixel is beneficial in discovering single isotope or multi isotope signal combinations that can be used to discriminate domains. In this regard, future work towards automated domain separation using cluster anal ysis, principle component analysis (Paul et al. 2014) or machine learning approaches is an attractive direction.

In Figure 5, we present phase masks created for element quantification overlaid with a microscope image of the PF12 sample; good agreement of the microscope image and LA ICP MS signal assigned phases is apparent. In Figure $5 d$ f, the phase specific quantification of iron is presented to illustrate how the phase masks (i.e., oxides, carbonates and sulfide) were used to quantify each element throughout the 

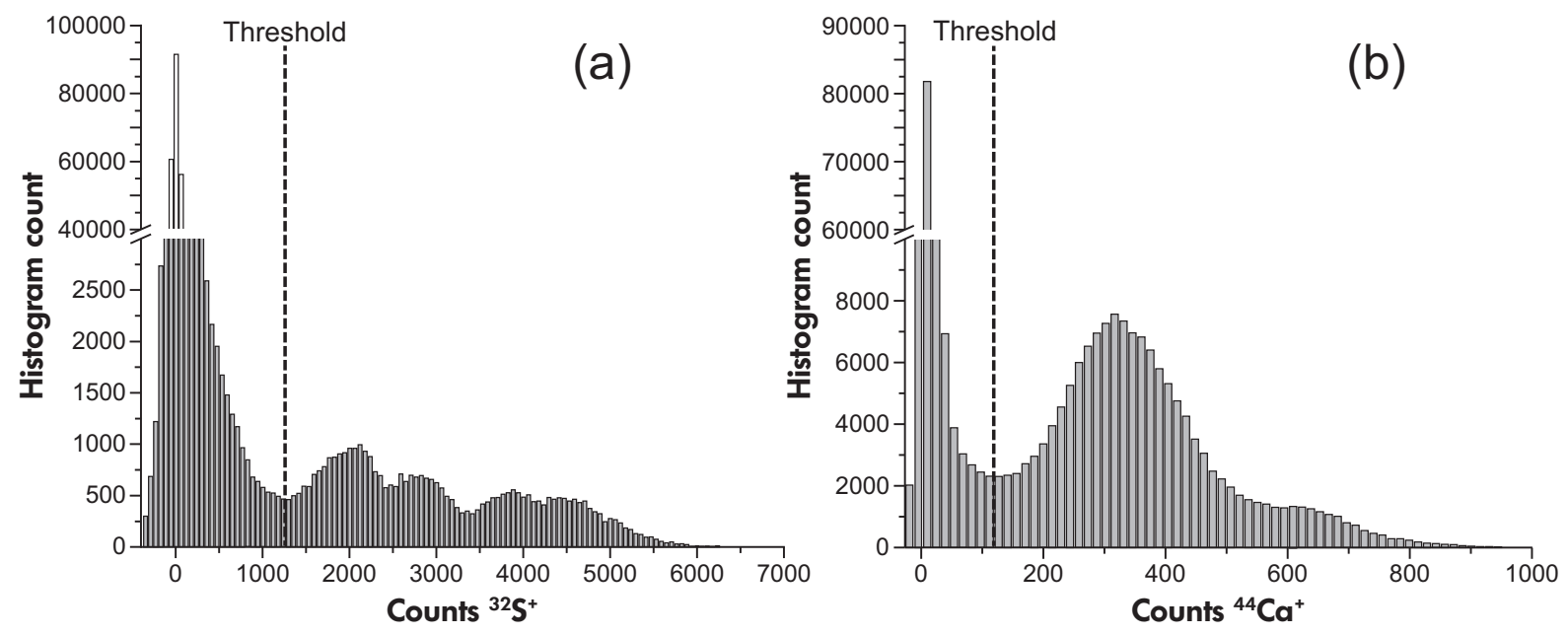

Figure 4. (a) Histogram of ${ }^{32} \mathrm{~S}^{+}$signals from all pixels in elemental image. A threshold of 1254 counts shows separation between the sulfide domain and the background. The broad background arises from the isobaric overlap of ${ }^{16} \mathrm{O}^{2+}$ as well as a large number of mixed-domain LA events, in which ablation occurred at a domain edge and thus ablated material from each of the adjoin domains. The multipeak structure of the histogram above the threshold is the result of multiple sulfide domains, that is, $\mathrm{ZnFeS}$ (more counts) and $\mathrm{PbS}$ (fewer counts). (b) Histogram of ${ }^{44} \mathrm{Ca}^{+}$singlepixel signals with a threshold of 132 counts to separate the $\mathrm{CaCO}_{3}$ phase from the oxide phase. Again, the broad background histogram is largely attributed to mixed-domain LA events from ablation at domain borders.

elemental images. Important to note is that it is not actually correct to define the composition of all pixels in the LA ICP MS image as single phase; some LA spots are actually composed of sample from more than one phase because the laser spot is at the junction of two or more phases of the rock sample. For pixels with isotope intensities higher than both the sulfide and carbonate thresholds, the sulfide domain was assigned. For pixels with all isotopes below the sulfide and carbonate thresholds (but still a partial ablation of sulfide or carbonate), quantification based on 100\% normalisation to the sum of oxides was performed. Partial ablation of phases clearly leads to a quantification error; this effect is termed the 'halo-effect' in LA ICP MS imaging (van Elteren and Vanhaecke 2016) because lower intensity pixels outline features of the image. The impact of the halo effect on image quality is dependent on the spot size or lateral resolution of the LA and the size of the features imaged. Strategies to deconvolute the contribution of each phase from a single pixel would be of interest; however, poor ion statistics obtained from the small amount of material ablated per laser shot combined with element redundancy between phases makes such deconvo lution challenging.

\section{Comparison of quantitative imaging and hole- drilling data}

To examine the accuracy of the 100\% normalised quantified element mass fractions obtained by imaging LA
ICP ToF MS we selected a small region $(\sim 200 \times 300 \mu \mathrm{m})$ of the PF12 sample that resides completely within the Si Al oxide phase and performed conventional hole drilling LA ICP MS analysis. For this analysis, a laser spot diameter of $44 \mu \mathrm{m}$ and a laser repetition rate of $10 \mathrm{~Hz}$ were used, and elements were quantified against reference material NIST SRM 610 with ${ }^{29} \mathrm{Si}$ as the internal standard; Si mass fraction in this phase was determined by Electron Microprobe analysis.

In Figure 6, the average mass fraction determined from five different hole drilling LA ICP MS experiments is plotted against the median mass fractions of elements in image pixels across the identical region of the rock sample. For hole drilling quantification, only the first $2.3 \mathrm{~s}$ of each ablation was used for quantification because this most closely matches the surface concentration of elements, as was determined with elemental imaging. At greater time points along hole drilling experiments (i.e., deeper laser sampling position), large variation in isotopic signals was obtained due to sample inhomogeneity at depth. As shown in Figure 6, mass fractions determined by hole drilling LA and LA imaging are generally correlated; major outliers include Al (two times higher mass fraction in hole drilling experiments), Zr and Cs. In the silica alumina phase of the sample, $\mathrm{Zr}$ and Cs exist mostly in clumps of localised high mass fractions; when the median pixel value of the LA ICP ToF MS image area is calculated, the 

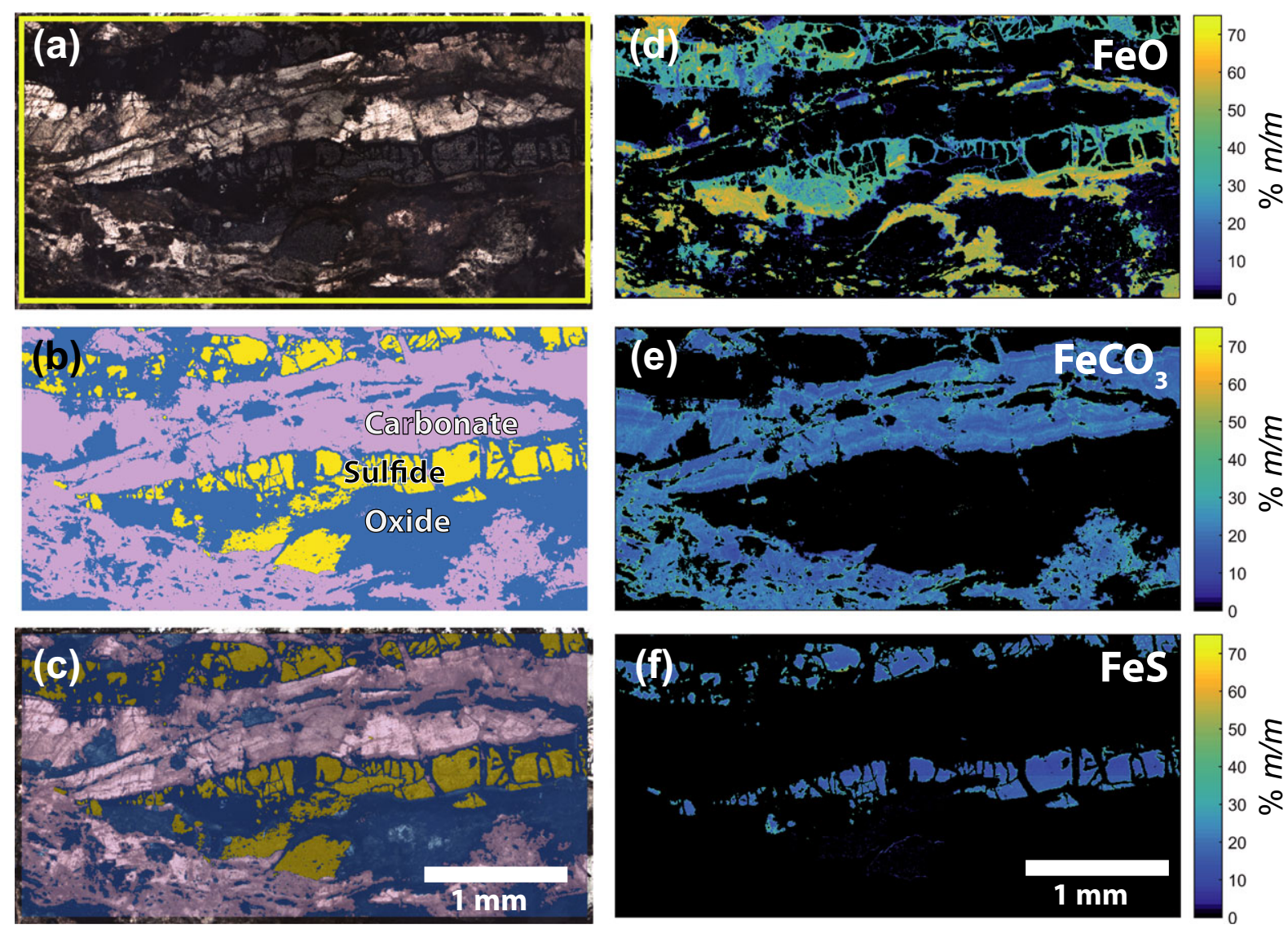

Figure 5. (a) White-light microscope photomicrograph of the ablated region of PF 12 sample. (b) For $100 \%$ normalisation to the sum of element species, masks for the carbonate, oxide and sulfide phases were generated using pixel-intensity thresholds as discussed in Figure 4. (c) Carbonate, sulfide and oxide masks superimposed on sample microscope image. (d f) Quantified images $(\% \mathrm{~m} / \mathrm{m}$ ) of iron species for each of the three domains. A composite concentration image for iron mass fraction can be made by summing the three Fe-species-dependent concentration images.

relatively few high concentration pixels have little influence on this value, and the average mass fraction determined by hole drilling LA experiments is higher. Elemental images of $\mathrm{Zr}$ and $\mathrm{Cs}$ are provided in Figure S3. In the case of Al, the difference between hole drilling and imaging exper iments remains unclear: heterogeneity of the internal standard (i.e., Si) in the Si Al phase could cause mass fraction discrepancies, or matrix mismatch between NIST SRM 610 reference material and the Si Al phase of the Zuccale Fault Rock sample might be problematic. Nonetheless, in both hole drilling and imaging experiments, Si and Al are the major elements, and 100\% mass normalisation quantification allows for correlation of determined elemental mass fractions across at least five orders of magnitude, which indicates that the $100 \%$ mass normalisation quantification of each image pixel is effective, even with the high lateral resolution of $5 \mu \mathrm{m}$.

\section{Geological interpretation of compositional maps}

The quantification approach described above provides a set of compositional maps of major (Figure 7) and minor/ trace rock components (Figure 8). In Figure 7, components are reported in units of per cent mass of their oxide forms, except for Figures 7e, i, which are reported as per cent mass sulfides. In Figure S4, we present the same element maps, but as absolute elemental mass fractions $\mu \mathrm{g} \mathrm{g}^{-1}$ and plotted as the logarithm on a false colour scale. It is important to note that while these concentrations reflect the true mass fractions of each element, they also provide direct information on the mineralogical composition across the images. Indeed, such information is allowed by the correspondence between petrographic images (Figures $2 a c$ and $5 a$ ) and single element compositional maps, which lead to an accurate identification of the constituent minerals. 

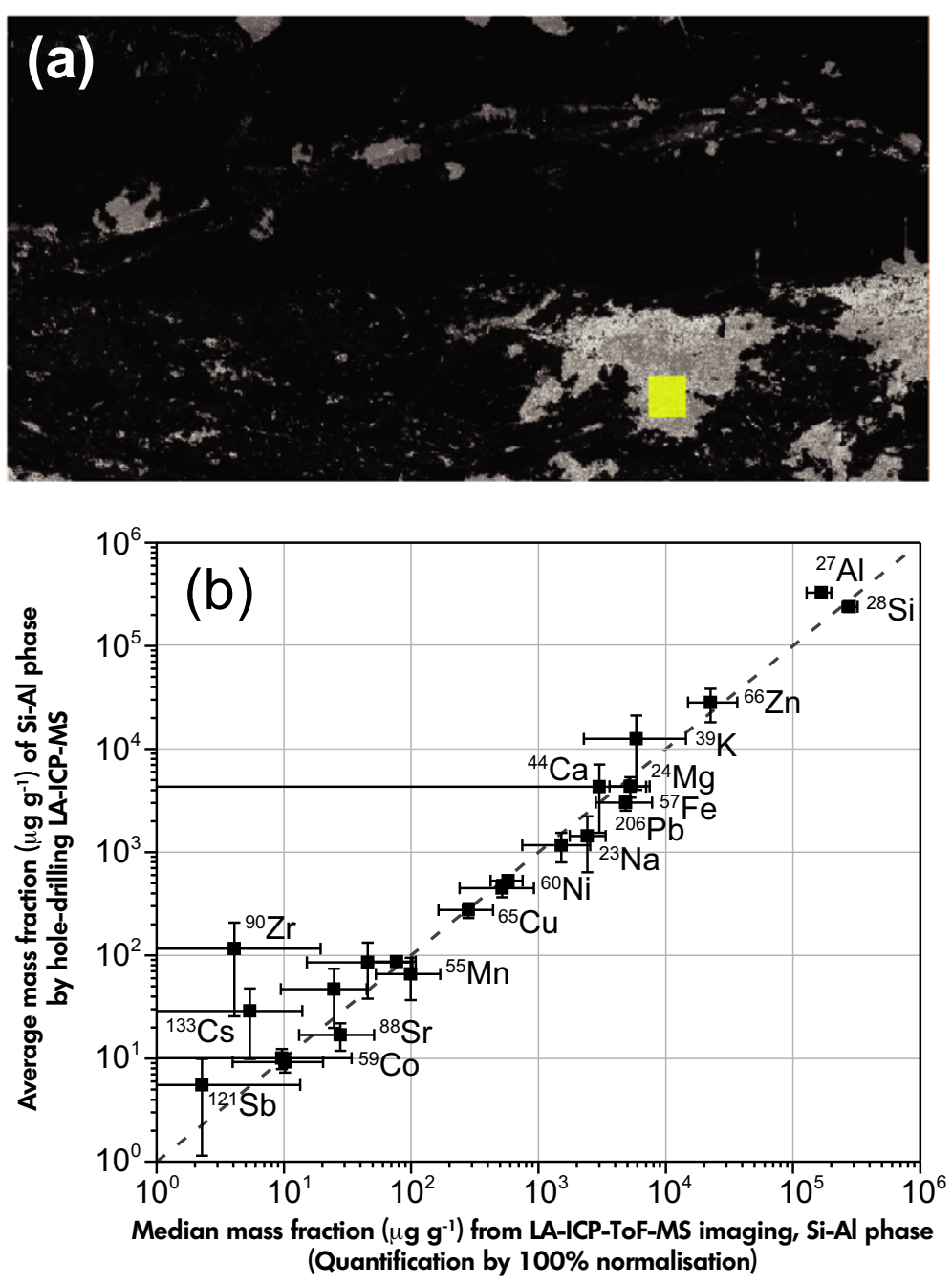

Figure 6. Comparison of average elemental mass fractions determined by hole-drilling LA-ICP-ToF-MS with median mass fractions determined by imaging LA-ICP-ToF-MS for a select region of the Si-Al phase of the PF1 2 sample. (a) Yellow squared indicated region of the Si-Al phase elemental image selected for analysis. (b) Correlation of mass fractions determined by two LA-ICP-MS analyses. Elements with median mass fractions $>1 \mu \mathrm{g} \mathrm{g}^{1}$ are plotted. Select data points are labelled with isotope used for quantification. Vertical error bars indicate \pm standard deviation and horizontal error bars represent the first and third quartiles (i.e., $25 \%$ and $75 \%$ ) of pixel concentrations.

Two considerations can be made from the inspection of the compositional maps presented here. First, the spatial distribution of major, minor and trace components can be coupled with petrographic observations not only to identify the mineralogical composition of the rock, but also to determine the chemical heterogeneity of individual phases within the analysed area. For instance, the highest ranges of $\mathrm{SiO}_{2}$ (Figure $7 \mathrm{a}$ ) and $\mathrm{Al}_{2} \mathrm{O}_{3}$ (Figure $7 f$ ) mass fractions in the analysed area are found where the silica clumps occur. These variations necessarily correspond to regions in which the silica bulk composition is controlled by the relative substitutions of $\mathrm{Si}$ and Al within structure of the amorphous solid. Thus, the constructed maps identify Si and Al as the major components of the amorphous silica clumps, but they allow also the identification of a large number of minor and trace components. In addition to $\mathrm{Al}_{2} \mathrm{O}_{3}$, our determinations show that important minor and trace components of amorphous silica are $\mathrm{Zn}$ (Figure 7i), $\mathrm{Na}_{2} \mathrm{O}$ (Figure 7i), Ga (Figure 8b), $\mathrm{Sn}$ (Figure $8 \mathrm{~g}$ ) and $\mathrm{Sr}$ (Figure $8 \mathrm{e}$ ). Lead mass fraction (Figure $7 \mathrm{j}$ ) is consistently high within silica clumps (of the order of thousands of $\mu \mathrm{g} \mathrm{g}^{-1}$ ) but the variations of its mass fractions are independent from $\mathrm{SiO}_{2}$ variations. Other minor/trace silica components not shown in Figures 7 and 8 are $\mathrm{K}(<3.2 \%$ $\mathrm{m} / \mathrm{m})$, Mo $\left(<1500 \mu \mathrm{g} \mathrm{g}^{-1}\right)$, W $\left(<1500 \mu \mathrm{g} \mathrm{g}^{-1}\right)$, Cr $\left(<1000 \mu \mathrm{g} \mathrm{g}^{-1}\right), \mathrm{Rb}\left(<300 \mu \mathrm{g} \mathrm{g}^{-1}\right)$ and $\mathrm{Cs}\left(<150 \mu \mathrm{g} \mathrm{g}^{-1}\right)$. All these components show spatial distributions that are either 

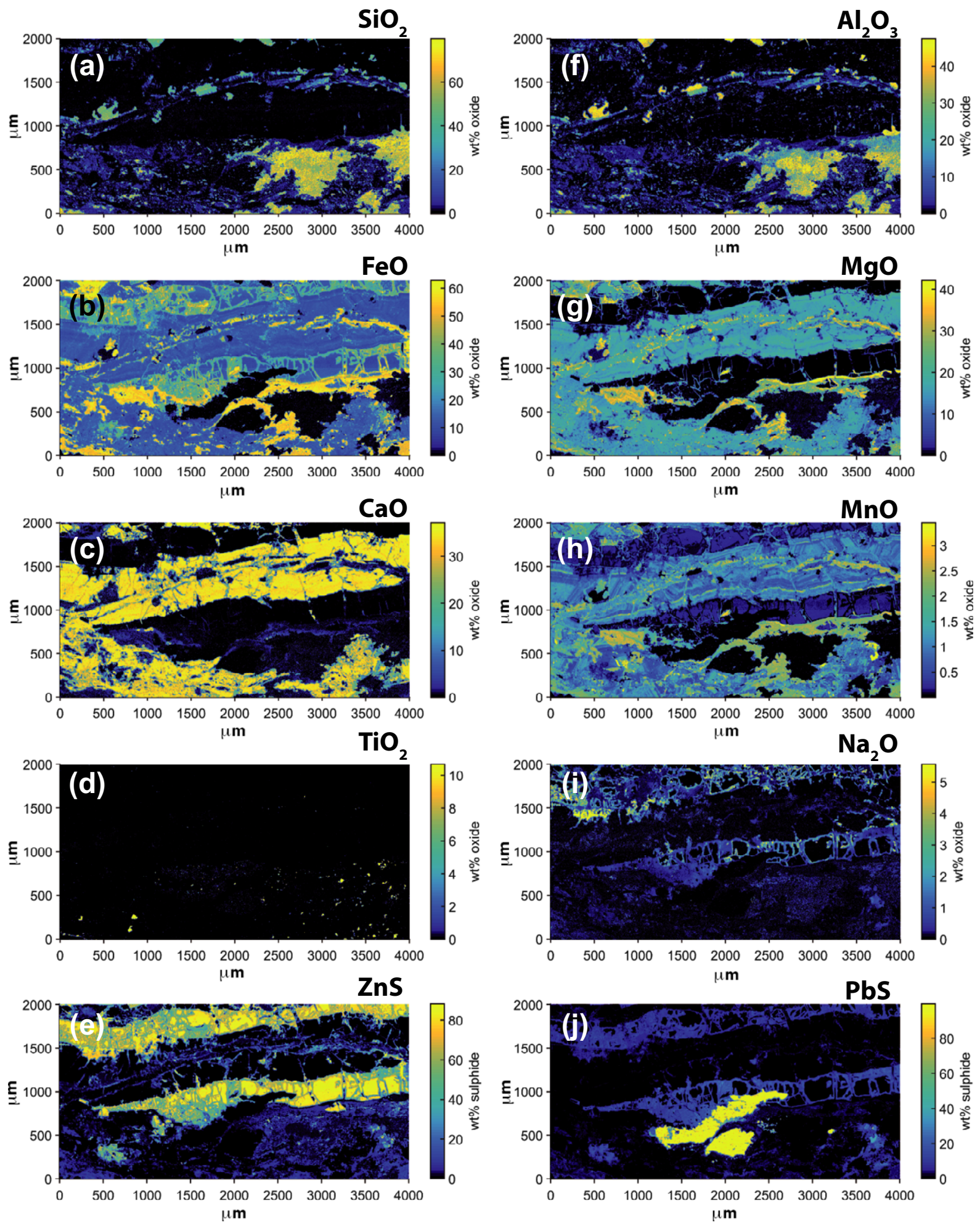

Figure 7. LA-ICP-ToF-MS images of major components of the Zuccale fault rock sample. False-colour scales of images correspond to the $\% \mathrm{~m} / \mathrm{m}$ oxide mass fractions ( $a d, f i$ ) or to the $\% \mathrm{~m} / \mathrm{m}$ sulfide for zinc (e) and lead ( $j$ ). The latter case provides a more detailed representation for elements with a broad mass fraction variation. For elemental images with mass fractions reported as $\% \mathrm{~m} / \mathrm{m}$ oxide, element species were actually calculated according to phasespecific (i.e., oxide, carbonate or sulfide) molecular stoichiometries. True mass fractions of each element were converted to $\% \mathrm{~m} / \mathrm{m}$ oxide for image display purposes. Colour scales span from $0 \% \mathrm{~m} / \mathrm{m}$ (black) to a maximum concentration value (white) such that $0.5 \%$ of pixels are saturated. 

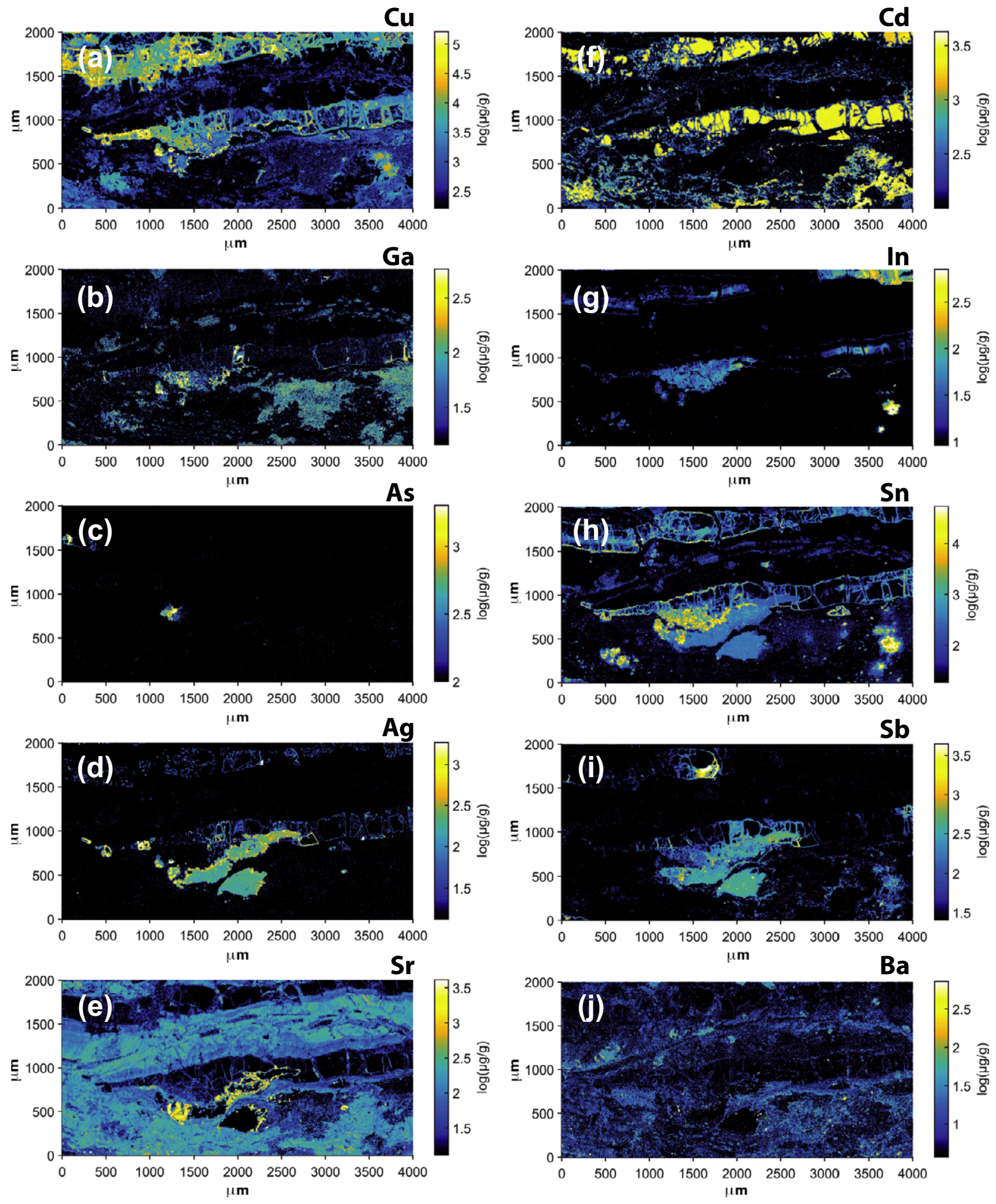

Figure 8. LA-ICP-TOF-MS images of minor and trace elements of the Zuccale fault rock sample. False-colour scales of the single-element images correspond to the log of element mass fractions in $\mu \mathrm{g} \mathrm{g}{ }^{~}$; colour scales span from the limit of detection (black) to a maximum mass fraction value (white) such that $0.05 \%$ of pixels are saturated. 
irregular $(\mathrm{K}, \mathrm{Rb})$ or spotty $(\mathrm{Mo}, \mathrm{W})$ within the clumps, and none of them occur exclusively within silica.

A second important consideration is that the compositional maps allow a microtextural analysis that would otherwise be difficult to carry out with other analytical techniques. For instance, the thin and continuous compositional banding displayed along the dolomite level by $\mathrm{FeO}$ (Figure 7b), $\mathrm{MgO}$ (Figure 7g), $\mathrm{MnO}$ (Figure $7 \mathrm{~h}$ ) and $\mathrm{Sr}$ (Figure 8e) corresponds to a primary compositional zoning of dolomite. This banding which is laterally continuous is shown in detail in Figure S5, where a uniform thickness of $4050 \mu \mathrm{m}$ can be evaluated for each individual band. Such delicate and continuous banding demonstrates unequivocally that the dolomite of the cataclasite formed as a result of an undisturbed growth, rather than from a brittle deformation event. Interestingly, the compositionally zoned dolomite is crosscut by a dense network of veinlets that extends into the adjacent sulfide levels. This network of thin veinlets provides evidence for brittle fracturing and replacement postdating the sulfide and dolomite precipitation in the cataclasite.

Other important observations can be made from the inspection of the LA ICP ToF MS compositional maps. The ochraceous phase is compositionally variable, and its variability is generated by changes in $\mathrm{SiO}_{2}, \mathrm{Al}_{2} \mathrm{O}_{3}, \mathrm{CaO}$ and $\mathrm{MgO}$ mass fractions rather than by significant variations of $\mathrm{FeO}$ content. This is evident from a comparison between the $\mathrm{FeO}$ map (Figure 7b) and those of $\mathrm{SiO}_{2}, \mathrm{Al}_{2} \mathrm{O}_{3}, \mathrm{CaO}$ and $\mathrm{MgO}$, which show that while $\mathrm{FeO}$ mass fraction is consistently high and $\geq 50 \% \mathrm{~m} / \mathrm{m}$ within the veinlets (bright areas of Figure $7 \mathrm{~b}$ ), those of all other components may vary by orders of magnitude (e.g., MgO). Such variations suggest a mineral composition made of a mixed oxide/hydroxide assemblage. Among the other major components, the ochraceous phase hosts consistently high, but variable, mass fractions of $\mathrm{MnO}$ (Figure 7h), Zn (Figure 7e), Pb (Figure 7i) and $\mathrm{Cu}$ (Figure 8a). Among the trace components, this phase shows extremely variable and spotty mass fractions of Sn (Figure 8h), Sb (Figure 8i), Ba (Figure 8j), and of (not shown) $U\left(<300 \mu \mathrm{g} \mathrm{g}^{-1}\right)$ and Th $\left(<100 \mu \mathrm{g} \mathrm{g}^{-1}\right)$. The highest $\mathrm{In}$ mass fraction of the analysed area (Figure $7 \mathrm{~g}$ ) was determined in a portion of the ochraceous phase that is enriched in $\mathrm{Sn}, \mathrm{Sb}, \mathrm{Cd}, \mathrm{Na}_{2} \mathrm{O}$ and $\mathrm{Co}$ (not shown) in addition to $\mathrm{FeO}, \mathrm{Zn}, \mathrm{Pb}$ and $\mathrm{Cu}$. A similar association was found in the portion of the analysed area with the highest measured As mass fractions (Figure 8c).

Similarly to what is shown for dolomite, sphalerite and galena, which occur in the foliated portion of sample PF12, show a range of textures and compositions. Sphalerite hosts high but variable mass fractions of $\mathrm{Cd}(<1 \% \mathrm{~m} / \mathrm{m}), \mathrm{Cu}$ $\left(<1000 \mu \mathrm{g} \mathrm{g}^{-1}\right), \mathrm{Pb}\left(<1000 \mu \mathrm{g} \mathrm{g}^{-1}\right)$ and $\ln (<300 \mu \mathrm{g} \mathrm{g}$ $\left.{ }^{1}\right)$ in addition to $\mathrm{Zn}$ and $\mathrm{Fe}$. Within galena, $\mathrm{Pb}, \mathrm{Sn}$ and $\mathrm{Sb}$ are uniformly distributed, but $\mathrm{Ag}$ is preferentially enriched at crystal rims. Sphalerite is cut by a network of veinlets that clearly control the replacement by a fine grained phase that hosts a large number of elements, namely $\mathrm{Zn}, \mathrm{Pb}, \mathrm{Fe}, \mathrm{Mg}$, $\mathrm{Cu}, \mathrm{Sn}, \mathrm{In}, \mathrm{As}, \mathrm{Sb}, \mathrm{Ag}, \mathrm{Cd}, \mathrm{Ga}$, and variable quantities of $\mathrm{Na}$, $\mathrm{Mn}, \mathrm{Ba}, \mathrm{Sr}, \mathrm{Ni}$ and REEs. Similar to what described for the mixed oxide ochraceous phase, this replacing fine grained phase cannot be explained by a single mineral, rather by a mineralogically complex oxide assemblage.

The high mass fraction spots of $\mathrm{TiO}_{2}$ within the sample (Figure $7 \mathrm{~d}$ ) are generated by relatively isolated, euhedral rutile crystals within the fault rock (Figure 2a, b). These euhedral crystals display a specific compositional and textural feature, which is the association of $\mathrm{Ti}, \mathrm{Nb}$, Ta and W (Figure S6). The exact spatial coincidence of these elements within these crystals indicates that the formation of such $\mathrm{Nb}$ Ta W rich rutile was an integral part of the cataclasite formation.

\section{Conclusions}

High resolution, quantitative LA ICP ToF MS elemental imaging proves to be a very effective tool to determine the chemical and mineralogical compositions of complex rock samples. This new imaging capability has become possible through recent technical developments in low dispersion LA systems and advanced ICP ToF MS instrumentation. The application of this imaging to the complex cataclasite sample of the Zuccale Fault shows that large format, high resolution images at lateral resolution of $5 \mu \mathrm{m}$ generate a combination of major, minor and trace element distributions of unprecedented geological utility. To obtain these mass fraction maps, we used a phase specific 100\% mass normalisation quantification strategy that takes into account the mass of major elements based on their molecular stoichiometries when combined with oxide $\left(\mathrm{O}^{2-}\right)$, carbonate $\left(\mathrm{CO}_{3}^{2}\right)$ or sulfide $\left(\mathrm{S}^{2-}\right)$ anions characteristic of the identified phases of each LA event. While this 100\% mass normalisation quantification seems to perform adequately, it would certainly be better to be able to directly measure the ablation yield of all major elements for improved quantification accuracy. In particular, combination of LA with a secondary approach, such as laser induced breakdown spectroscopy to measure oxygen, carbon and sulfur would be advantageous (Chirinos et al. 2014). In addition, a limitation of ICP ToF MS remains limited sensitivity for geologically important elements such as B, Li and K.

An important conclusion that can be drawn from our data is that part of the mineral assemblage of the Zuccale 
cataclasite could not form exclusively in a regime of brittle deformation (wearing), but from a mechanism of open space filling (undisturbed growth) that is unexpected in faults. This conclusion couples with the unexpected presence within the cataclasite minerals of a suite of elements including As, $\mathrm{Sb}$, In and $\mathrm{Ga}$, whose presence can be justified only by the introduction from an external source, presumably a hydrothermal fluid that was fluxed within the fault.

We anticipate a growth of popularity of high resolution, quantitative LA ICP ToF MS elemental imaging in the years to come in the scientific community. Such popularity will hopefully lead to improved models for a broad spectrum of geological applications.

\section{Acknowledgements}

Funding from University of Bologna is gratefully acknowl edged. Insightful discussions and feedbacks from G. Valdré, C. Collettini and R.E. Holdsworth inspired significantly the content of a previous version of this work. Alexander G. G. acknowl edges the Marie Curie International Incoming Fellowship from the European Union Seventh Framework Programme (FP7/ 2007 2013) under grant agreement no 624280.

† Both Corresponding authors contributed equally to this paper

\section{References}

Burger M., Gundlach-Graham A., Allner S., Schwarz G., Wang H.A.O., Gyr L., Burgener S., Hattendorf B., Grolimund D. and Gunther D. (2015)

High speed, high resolution, multielemental LA ICP ToF MS imaging: Part II. Critical evaluation of quantitative three dimensional imaging of major, minor and trace elements in geological samples. Analytical Chemistry, 87, 82598267.

Burger M., Schwarz G., Gundlach-Graham A., Kaeser D., Hattendorf B. and Gunther D. (2017)

Capabilities of laser ablation inductively coupled plasma time of flight mass spectrometry. Journal of Analytical Atomic Spectrometry, 32, 1946.

Bussweiler Y., Borovinskaya O. and Tanner M. (2017) Laser ablation and inductively coupled plasma time of flight mass spectrometry: A powerful combination for high speed multi elemental imaging on the micrometer scale. Spectroscopy, 32, 1420.

Chirinos J.R., Oropeza D.D., Gonzalez J.J., Hou H.M. Morey M., Zorba V. and Russo R.E. (2014)

Simultaneous 3 dimensional elemental imaging with LIBS and LA ICP MS. Journal of Analytical Atomic Spectrometry, $29,12921298$.

Collettini C. and Holdsworth R.E. (2004)

Fault zone weakening and character of slip along low angle normal faults: Insights from the Zuccale fault, Elba Italy. Journal of the Geological Society, 161, 1039 1051
Douglas D.N., Managh A., Reid H.J. and Sharp B.L (2015) High speed, integrated ablation cell and dual concentric injector plasma torch for laser ablation inductively coupled plasma mass spectrometry. Analytical Chemistry, 87, 1128511294

van Elteren J.T. and Vanhaecke F. (2016)

Angular resolution dependency in 2D LA ICP MS mapping The case for low dispersion laser ablation cells. Journal of Analytical Atomic Spectrometry, 31, 19982004.

van Elteren J.T., Izmer A., Sala M., Orsega E.F., Selih V.S., Panighello S. and Vanhaecke F. (2013)

3D laser ablation ICP mass spectrometry mapping for the study of surface layer phenomena A case study for weathered glass. Journal of Analytical Atomic Spectrom etry, 28, 9941004.

Giesen C., Wang H.A.O., Schapiro D., Zivanovic N., Jacobs A., Hattendorf B., Schuffler P.J., Grolimund D., Buhmann J.M., Brandt S., Varga Z., Wild P.J., Gunther D. and Bodenmiller B. (2014)

Highly multiplexed imaging of tumor tissues with subcel lular resolution by mass cytometry. Nature Methods, 11 , 417422.

Gratuze B. (1999)

Obsidian characterization by laser ablation ICP MS and its application to prehistoric trade in the Mediterranean and the Near East: Sources and distribution of obsidian within the Aegean and Anatolia. Journal of Archaeological Science, 26, 869881.

Guillong M., Meier D.L., Allan M.M., Heinrich C.A. and Yardley B.W.D. (2008)

SILLS: A MATLAB based program for the reduction of laser ablation ICP MS data of homogeneous materials and inclusions. In: Sylvester P. (ed.), Laser ablation ICP MS in the Earth sciences: Current practices and outstanding issues. Mineralogical Association of Canada Short Course Series, 328333

Gundlach-Graham A. and Gunther D. (2016)

Toward faster and higher resolution LA ICP MS imaging: On the co evolution of LA cell design and ICP MS instrumentation. Analytical and Bioanalytical Chemistry, 408, 26872695.

Gundlach-Graham A., Burger M., Allner S., Schwarz G., Wang H.A.O., Gyr L., Grolimund D., Hattendorf B. and Gunther D. (2015)

High speed, high resolution, multielemental laser ablation inductively coupled plasma time of flight mass spectrome try imaging: Part I. Instrumentation and two dimensional imaging of geological samples. Analytical Chemistry, 87, 82508258 .

Hattendorf B. and Gunther D. (2014).

Laser ablation inductively coupled plasma mass spectrometry (LA ICP MS). In: Gaugliz G. and Moore G.D.S. (eds), Handbook of spectroscopy. Wiley (Hoboken, USA) 647698.

Heinrich C.A., Pettke T., Halter W.E., Aigner-Torres M.r Audetat A., Gunther D., Hattendorf B., Bleiner D. Guillong M. and Horn I. (2003)

Quantitative multi element analysis of minerals, fluid and melt inclusions by laser ablation inductively coupled plasma mass spectrometry. Geochimica et Cosmochimica Acta, 67, 34733497. 
references

Hendriks L., Gundlach-Graham A., Hattendorf B. and Gunther D. (2017)

Characterization of a new ICP ToF MS instrument with continuous and discrete introduction of solutions. Journal of Analytical Atomic Spectrometry, 32, 548561.

Jochum K.P. and Nohl U. (2008)

Reference materials in geochemistry and environmental research and the GeoReM database. Chemical Geology, 253, 5053.

Keller J.V.A. and Coward M.P. (1996)

The structure and evolution of the northern Tyrrhenian Sea. Geological Magazine, 103, 116.

Large R.R., Danyushevsky L., Hollit C., Maslennikov V., Meffre S., Gilbert S., Bull S., Scott R., Emsbo P., Thomas H., Singh B. and Foster J. (2009)

Gold and trace element zonation in pyrite using a laser imaging technique: Implications for the timing of gold in orogenic and Carlin style sediment hosted deposits. Eco nomic Geology, 104, 635668

Leach A.M. and Hieffie G.M. (2001)

Standardless semiquantitative analysis of metals using single shot laser ablation inductively coupled plasma time of flight mass spectrometry. Analytical Chemistry, 73, 29592967.

Leach A.M. and Hieftje G.M. (2002)

Factors affecting the production of fast transient signals in single shot laser ablation inductively coupled plasma mass spectrometry. Applied Spectroscopy, 56, 6269.

\section{Liu Y., Hu Z., Gao S., Gunther D., Xu J., Gao C. and Chen} H. (2008)

In situ analysis of major and trace elements of anhydrous minerals by LA ICP MS without applying an internal standard. Chemical Geology, 257, 3443.

Longerich H.P., Jackson S.E. and Gunther D. (1996) Laser ablation inductively coupled plasma mass spectro metric transient signal data acquisition and analyte concentration calculation. Journal of Analytical Atomic Spectroscopy, 11, 899904

Musumeci G., Mazzarini F. and Cruden A.R. (2015) The Zuccale Fault, Elba Island, Italy: A new perspective from fault architecture. Tectonics, 34, 11951218

Paul B., Woodhead J.D., Paton C., Hergt J.M., Hellstrom J. and Norris C.A. (2014)

Towards a method for quantitative LA ICP MS imaging of multi phase assemblages: Mineral identification and analysis correction procedures. Geostandards and Geo analytical Research, 38, 253263

Petrus J.A., Chew D.M., Leybourne M.I. and Kamber B.S. (2017)

Anew approach to laser ablation inductively coupled plasma mass spectrometry (LA ICP MS) using the flexible map interro gation tool 'Monocle'. Chemical Geology, 463, 7693.

Pettke T., Oberli F., Audétat A., Guillong M., Simon A.C., Hanley J.J. and Klemm L.M. (2012)

Recent developments in element concentration and isotope ratio analysis of individual fluid inclusions by laser ablation single and multiple collector ICP MS. Ore Geology Reviews, 44, 1038.
Poli G. and Peccerillo A. (2016)

The Upper Miocene magmatism of the Island of Elba (Central Italy): Compositional characteristics, petrogenesis and implications for the origin of the Tuscany Magmatic Province. Mineralogy and Petrology, 1 10, 421445.

Schilling G.D., Andrade F.J., Barnes 4th J.H., Sperline R.P., Denton M.B., Barinaga C.J., Koppenaal D.W. and Hieftje G.M. (2007)

Continuous simultaneous detection in mass spectrometry Analytical Chemistry, 79, 76627668.

Smith S.A.F. and Faulkner D. (2010)

Laboratory measurements of the frictional properties of the Zuccale low angle normal fault, Elba Island, Italy. Journal of Geophysical Research, 1 15, B02407. https://doi.org/ 10.1029/2008JB006274

Sylvester P. and Jackson S.E. (2016)

Studying the Earth with LA ICP MS. Elements, 12

Tabersky D., Nishiguchi K., Utani K., Ohata M., Dietiker R., Fricker M.B., de Maddalena I.M., Koch J. and Gunther D. (2013)

Aerosol entrainment and a large capacity gas exchange device (Q GED) for laser ablation inductively coupled plasma mass spectrometry in atmospheric pressure air. Journal of Analytical Atomic Spectrometry, 28, 831842.

Tanelli G., Benvenuti M., Costagliola P., Dini A., Lattanzi P., Maineri C., Mascaro I. and Ruggieri G. (2001) The iron mineral deposits of Elba Island: State of the art. Ofioliti, 26, 239248

Ubide T., McKenna C.A., Chew D.M. and Kamber B.S. (2015)

High resolution LA ICP MS trace element mapping of igneous minerals: In search of magma histories. Chemical Geology, 409, 157168

Ulrich T., Kamber B.S., Jugo P.J. and Tinkham D.K. (2009)

Imaging element distribution patterns in minerals by laser ablation inductively coupled plasma mass spectrometry (LA ICP MS). The Canadian Mineralogist, 47, 1001 1012.

Van Malderen S.J., van Elteren J.T. and Vanhaecke F. (2015)

Submicrometer imaging by laser ablation inductively cou pled plasma mass spectrometry via signal and image deconvolution approaches. Analytical Chemistry, 87 61256132

Van Malderen S.J.M., Managh A.J., Sharp B.L. and Vanhaecke F. (2016)

Recent developments in the design of rapid response cells for laser ablation inductively coupled plasma mass spectrometry and their impact on bioimaging applica tions. Journal of Analytical Atomic Spectrometry, 31, 423439 
references

Van Malderen S.J., Laforce B., Van Acker T., Nys C., De Rijcke M., de Rycke R., De Bruyne M., Boone M.N., De Schamphelaere K., Borovinskaya O., De Samber B.,

Vincze L. and Vanhaecke F. (2017)

Three dimensional reconstruction of the tissue specific mul tielemental distribution within Ceriodaphnia dubia via multimodal registration using laser ablation ICP mass spectrometry and $X$ ray spectroscopic techniques. Analyt ical Chemistry, 89, 41614168.

Wang H.A.O., Grolimund D., Giesen C., Borca C.N., Shaw-Stewart J.R.H., Bodenmiller B. and Gunther D. (2013)

Fast chemical imaging at high spatial resolution by laser ablation inductively coupled plasma mass spectrometry. Analytical Chemistry, 85, 1010710116.

Woodhead J.D., Hellstrom J., Hergt J.M., Greig A. and Maas R. (2007)

Isotopic and elemental imaging of geological materials by laser ablation inductively coupled plasma mass spectrom etry. Geostandards and Geoanalytical Research, 31,

331343

\section{Supporting information}

The following information may be found in the online version of this article:

Figure S1. Attenuation of selected isotopes due to application of notch filter centred on $\mathrm{m} / \mathrm{z} 215$.

Figure S2. Single shot (i.e., single pixel) limits of detection.

Figure S3. Quantified elemental images of Cs and Zr with zoom in views of Si/Al domain of Zuccale Fault rock sample.

Figure S4. LA ICP ToF MS images with absolute mass fractions $\left(\mu \mathrm{g} \mathrm{g}^{-1}\right.$ ) plotted on $\log _{10}$ scale.

Figure S5. Quantified elemental image of Mn.

Figure S6. LA ICP ToF MS images of Ti, W, Ta and Nb.

Table S1. Typical operating conditions for imaging experiments.

Table S2. Elements quantified in elemental images of the Zuccale fault rock and correction factors.

Table S3. Typical operating conditions for hole drilling experiments.
This material is available from: http://onlinelibrary.wiley.c om/doi/10.1111/ggr.12233/abstract (This link will take you to the article abstract). 